\title{
Optimal Partner Combination for Joint Distribution Alliance using Integrated Fuzzy EW-AHP and TOPSIS for Online Shopping
}

\author{
Yandong $\mathrm{He}^{1}$, Xu Wang ${ }^{1,2, *}$, Yun Lin ${ }^{1,2}$ and Fuli Zhou ${ }^{1}$ \\ 1 College of Mechanical Engineering, Chongqing University, Chongqing 400030, China; \\ ydhe602@163.com (Y.H.); linyun313@163.com (Y.L.); deepbreath329@outlook.com (F.Z.) \\ 2 Chongqing Key Laboratory of Logistics, Chongqing University, Chongqing 400030, China \\ * Correspondence: 20120713255@cqu.edu.cn or wx921@163.com; Tel./Fax: +86-23-6510-5109 \\ Academic Editor: Kannan Govindan \\ Received: 13 January 2016; Accepted: 30 March 2016; Published: 7 April 2016
}

\begin{abstract}
With the globalization of online shopping, deterioration of the ecological environment and the increasing pressure of urban transportation, a novel logistics service mode-joint distribution (JD) - was developed. Selecting the optimal partner combination is important to ensure the joint distribution alliance (JDA) is sustainable and stable, taking into consideration conflicting criteria. In this paper, we present an integrated fuzzy entropy weight, fuzzy analytic hierarchy process (fuzzy EW-AHP) and fuzzy technique for order preference by similarity to an ideal solution (TOPSIS) approach to select the optimal partner combination of JDA. A three-phase approach is proposed. In the first phase, we identify partner combination evaluation criteria using an economy-society-environment-flexibility (ESEF) framework from a perspective that considers sustainability. In the second phase, the criteria weights and criteria combination performance of different partner combinations were calculated by using an integrated fuzzy EW-AHP approach considering the objective and subjective factors of experts. In the third phase, the JDA partner combinations are ranked by employing fuzzy TOPSIS approach. The sensitivity analysis is considered for the optimal partner combination. Taking JDA in Chongqing for example, the results indicate the alternative partner combination 3 (PC3) is always ranked first no matter how the criteria weights change. It is effective and robust to apply the integrated fuzzy EW-AHP and TOPSIS approach to the partner selection of JDA.
\end{abstract}

Keywords: online shopping logistics; joint distribution (JD); partner combination selection; fuzzy entropy weight, fuzzy analytic hierarchy process (fuzzy EW-AHP); fuzzy technique for order preference by similarity to an ideal solution (fuzzy TOPSIS)

\section{Introduction}

With the rapid development of China's economy and the internet's rapid popularization, online shopping has become one of the most important online behaviors. On 11 November 2015, on Alibaba's annual day of discounts called the "Double 11 Shopping Carnival", Taobao and Tmall (two e-commerce enterprises in China) generated more than $\$ 14.14$ billion in sales and 678 million orders in just $24 \mathrm{~h}$ [1]. However, the rapid development of online shopping has brought serious challenges to logistics. For example, for online shopping logistics service enterprises, the problems of high logistics costs, low operation efficiency and low resources utilization are serious [2-4], and for end-customers, the timeliness and personalized needs of logistics distribution cannot be fully satisfied $[2,5,6]$.

In 2013, to cope with the online shopping logistics problem, the National Urban Distribution Development Guidelines issued by the Ministry of Commerce of China promoted urban synergetic 
distribution to deal with the challenges posed by online shopping [7]. In 2014, the Medium and Long Term Development Plan for Logistics from 2014 to 2020 issued by the China's State Council set a development goal of cooperative operations among logistics enterprises to satisfy buyers' personalized and diversified demand and reduce traffic pressure [8]. Experts explored solutions for the online shopping logistics problem and proposed a novel logistics service mode, namely joint distribution (JD) [9-11]. Currently, JD has drawn more and more attention from government, e-commerce enterprises and logistics enterprises. Development of JD is an effective way to reduce logistics costs, increase the utilization of logistics resources, improve the efficiency of logistics operations and satisfy the personalized demand of the last mile delivery for end customers [12-16]. In addition, sharing logistics resources such as distribution vehicles and warehouse centers can minimize traffic congestion and environmental impacts [17]. Any logistics enterprise stands to lose if trying to "go it alone" in the e-commerce environment [12].

Therefore, logistics enterprises must collaborate with each other to realize the integration of resources, information sharing and business collaboration [12,18]. General logistics service providers strongly believe in the potential benefits of cooperation to increase their profitability or to improve the quality of their services [19]. This makes it imperative to assess alternatives to build a joint distribution alliance (JDA) among logistics enterprises and identify right technology for partner selection that can assist them to achieve operational efficiency for online shopping logistics distribution. However, existing information in this area of partner selection mainly concentrates on the evaluation of a single logistics enterprise without taking into account the partner combination. The alliance consisting of the best partners is not necessarily a high-performance one [20]. Therefore, the performance of partner combinations criteria in the alliance is evaluated in this paper, not the single partner.

The methodologies for partner combination selection of JDA can be classified into four main categories: multi-criteria decision making approaches (MCDM), empirical studies, optimization approaches and hybrid approaches based on a combination of two or more of above. The MCDM methods [21-23] include AHP [24], Preference Ranking Organization Methods for Enrichment Evaluations (PROMETHEE) [25], TOPSIS [26], Vlsekriterijumska Optimizacija I Kompromisno Resenje (VIKOR) [27], Elimination Et Choice Translating Reality (ELECTRE) [28] etc. Chen et al. [29] establish a mechanism for partner selection that emphasizes the relation of criteria and motivation, taking the motivations of different enterprises' needs for establishing strategic alliances. Liao et al. [30] develop a hesitant fuzzy linguistic VIKOR method (HFL-VIKOR), motivated by the traditional VIKOR method. This method uses a hesitant fuzzy linguistic term set to represent decision makers' qualitative assessments in the processes of decision making. Feng et al. [31] propose a fuzzy multiple attribute decision-making (FMADM) method, which integrated the assessment data of individual and collaborative utilities, to achieve the final ranking of all candidate partners for partner selection of co-development alliances. Note that the collaborative attributes include resource complementarity, motivation and goal correspondence, overlapping knowledge bases and compatible cultures. Govindan et al. [32] focus on green supplier evaluation and selection that considered environmental factors based on the literature review, while the limitations of current literature and the future direction of green supplier selection were analyzed. In addition, Govindan et al. [33] also point out that social and environmental factors should be considered in the future development of logistics.

Empirical studies employed a variety of modes to collect data such as questionnaires, case studies, expert interviews and so on. Pidduck [34] investigates a number of software industry enterprises in a supply chain and found that the collaborative partner selection was complex. The criteria of partner selection involved hard constraints, resource availability, social network, reputation, politics, ambiguity, personal friendship and prior relationships. Cui et al. [35] establishes a determining-factor model for partner selection taking four hypothesized determining factors (mutual compatibility and degree of mutual trustworthiness, partners' technical innovation, intellectual property right and availability of partners' human capital) into consideration, based on the analysis of theoretical literature and data from an empirical survey questionnaire. Brian and Lisa [36] explore small innovative firms' motives 
for selecting university partners. Four types of motives including risk-reducing, cost-reducing, value creating and enabling motives were listed. The firms paid more attention to the enabling motives retaining flexibility and adaptability in commercializing the early-stage innovations.

Optimization methods involve minimizing or maximizing the objective function with a set of constraints. Amid et al. [37] develop a fuzzy multi-objective linear model to overcome the vagueness and imprecision of information to select the right suppliers. The fuzzy sets theory was used to handle uncertainty and the objectives were to minimize the net cost, minimize the rejected items and minimize the net late deliveries. Yeh and Chuang [38] introduce green criteria into the framework of partner criteria and developed an optimum mathematical planning model for green partner selection. The model involved four objectives such as cost, time, product quality and green appraisal score. Two multi-objective genetic algorithms were adopted to find the set of Pareto-optimal solutions. Niu et al. [39] evaluate the candidate partners by investigating five attributes including cost, time, quality, reputation and risk in virtual enterprises and develop an enhanced ant colony optimizer (ACO) to address the partner selection problem. Dao et al. [40] propose an innovative decision support system for partner selection in virtual enterprises using genetic algorithm (GA) with a unique dynamic chromosome representation and genetic operation. Wan et al. [41] propose a new intuitionistic fuzzy linear programming model for the selection of logistics outsourcing providers. For the fuzzy information, the intuitionistic fuzzy linear programming model was solved by developed three kinds of approaches including the optimistic, pessimistic and mixed approaches depended on the non-membership functions.

The hybrid methods employ a combination of the methods stated above. Awasthi et al. [18] present a fuzzy benefit-cost-opportunity-risk and gray relational analysis (BOCR-GRA) approach to collaboration partner selection of urban logistics planning with uncertainty. The evaluation criteria was identified using a BOCR framework, namely benefits, costs, opportunities and risks. Then GRA and five BOCR scoring methods were employed to select the optimal collaboration partner. Erkayman et al. [42] evaluate the third-party logistics (3PL) provider by using the integrated fuzzy AHP and TOPSIS methods which considered price, general reputation, customer services, on-time delivery, information technologies and flexibility as evaluation criteria. Su and Chen [43] develop a multilevel grey evaluation model combining grey evaluation and AHP. Four classification criteria of cost, service quality, cooperation reliability and comprehensive strength were designed from the long term cooperation perspective. Büyüközkana et al. [44] propose a three-phase strategic alliance partner selection method in electronic logistics value chain. The first phase identified the strategic main and criteria of the alliance partner selection including strategic and business excellence. The second phase calculated the criteria weights using fuzzy AHP method. The third and final phase was to conduct fuzzy TOPSIS to obtain the optimal partner. Li et al. [45] propose a customer satisfaction evaluation method of customized product development based on Voice-of-Customer $(\mathrm{VoC})$ through integrating entropy weight and AHP method.

In general, fuzzy set theory is used to cope with the lack of quantitative data and uncertainty on the decision maker's preference. The linguistic ratings of decision makers or experts are transformed as triangular fuzzy numbers. In this paper, we address the problem of JD among online shopping logistics enterprises to build a high-performance JDA. Our goal is to select the optimal partner combination by evaluating the partner combination performance for criteria with uncertainty. The main contributions of this paper are as follows:

(1) This is the first study that provides a complete and detailed list of evaluation criteria from the four aspects of economy, society, environment and flexibility for partner combination selection regarding online shopping from a sustainability perspective.

(2) In view of the problem that the index weight of TOPSIS evaluation method is difficult to determine, this paper uses the integrated fuzzy EW-AHP to determine the index weight, taking objective and subjective factors of experts into consideration. Then the fuzzy TOPSIS-based MCDM 
method is developed for a partner combination selection of JDA, which extends the application of the fuzzy TOPSIS method.

(3) In order to obtain better insight into the partner combination selection, a sensitivity analysis is performed to assess the impact of the index weight on final results, improving the outcome on uncertain partner combination selections.

The rest of this paper is organized as follows: Section 2 provides an economy-societyenvironment-flexibility (ESEF) framework to identify the evaluation criteria. In Section 3, we propose an integrated fuzzy EW-AHP and TOPSIS method for partner combination selection. A numerical application is presented in Section 4 . Section 5 provides results and sensitivity analysis to evaluate the rationality and robustness of the results. The conclusion is provided in Section 6.

\section{Identifying the Evaluation Criteria Based on an ESEF Framework}

It is very important to select appropriate scientific evaluation criteria for the partner combination selection of JDA. In this paper, the index system, including economy, society and environmental factors, is considered $[18,46]$, based on the characteristics of online shopping logistics, e.g., personalized demand of the last mile delivery for end customers $[6,17,47]$, flexibility criteria is also considered. Therefore, the evaluation index system for the partner combination selection of JDA is built using the economy-society-environment-flexibility framework (ESEF) from a sustainability perspective. The sustainability of JDA is reflected comprehensively by four groups of criteria, namely economy, society, environment and flexibility. Further, the sub-criteria are obtained based on our practical experience using an online shopping logistics project (City Joint Distribution for Online Shopping Logistics) in China. The final criteria system contains 15 criteria (Figure 1).

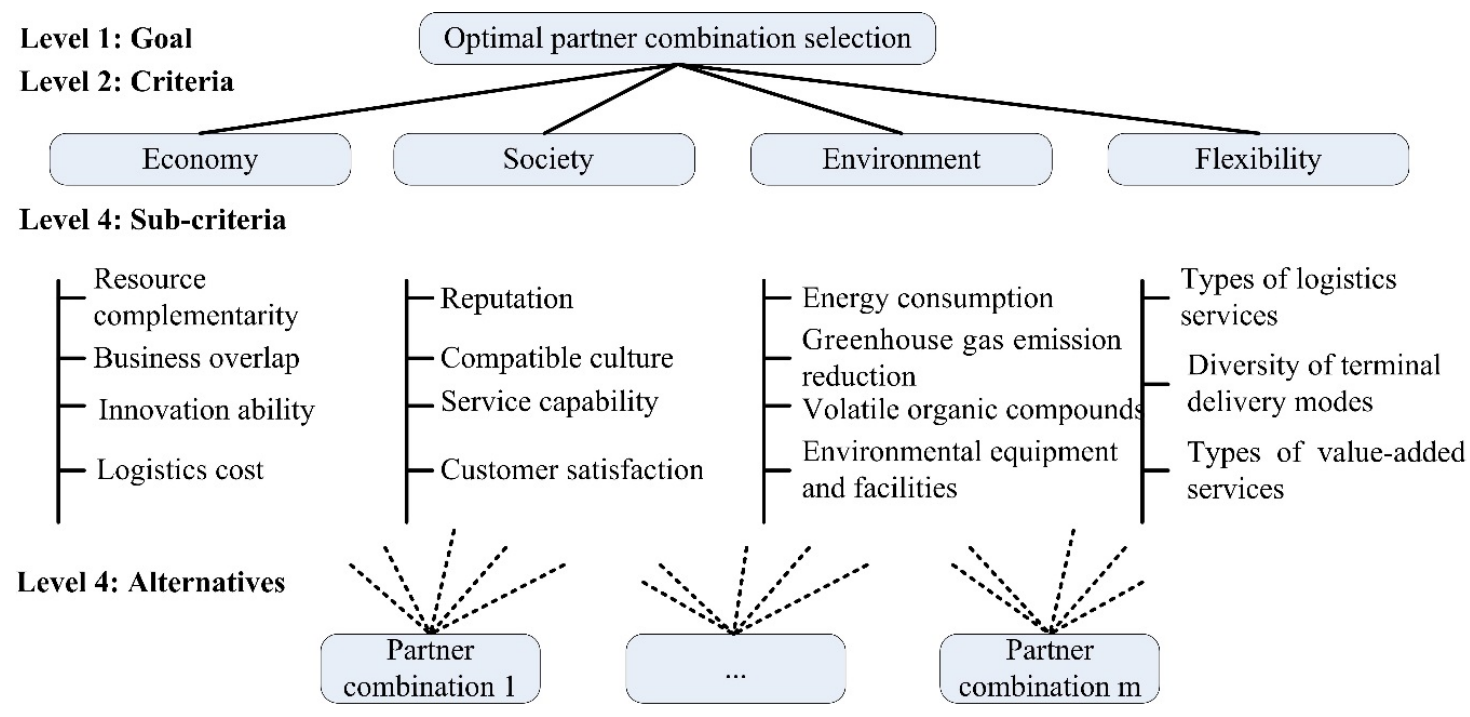

Figure 1. Hierarchy of the partner combination selection of joint distribution alliance (JDA).

\subsection{Economic Criteria}

The sub-criteria affiliated with the economic criteria for partner combination selection of JDA are summarized as follows:

(1) Resource complementarity (C1): Refers to the diverse resource endowments. The enterprises of JDA can learn from each other and service customers on the basis of the resources held by partners $[48,49]$.

(2) Business overlap (C2): Refers to the degree of similarity in business among these alternatives. The more similar the business is, the fiercer the competition is among partners. Therefore, 
the large similarity of business among these alternatives can have a negative impact on the sustainability and stability of the alliance.

(3) Innovation ability (C3): Refers to the management of the innovation and technology of enterprises. The alliance that consists of enterprises with strong innovation ability are vastly more competitive [36].

(4) Logistic costs (C4): Includes transportation, warehouse, management and information process costs.

\subsection{Societal Criteria}

Four sub-criteria affiliated with societal criteria for partner combination selection of JDA are summarized as follows:

(1) Reputation (C5): Refers to the social assessment of enterprises. Reputation will be one of the key factors for the future stability and successful implementation of an alliance [50].

(2) Compatible culture (C6): Refers to the similarity and openness of enterprise culture. Compatible culture, which has a significant positive effect on the stability and sustainability of an alliance, is viewed as fundamental in the decision-making process [51].

(3) Service capability (C7): Refers to the number of orders that can be completed by partner combinations.

(4) Customer satisfaction (C8): Refers to customer satisfaction levels, one of the most important criteria in the optimal partner combination selection.

\subsection{Environmental Criteria}

Four sub-criteria affiliated with environmental criteria for partner combination selection of JDA are selected as follows:

(1) Energy consumption (C9): Measures the energy consumption when completing a certain number of orders.

(2) Greenhouse gas (GHG) emission reduction (C10): The partner combination consisting of these environmental enterprises will emit fewer environmental pollutants (such as $\mathrm{CO}_{2}$ and $\mathrm{CH}_{4}$ ) in their daily operations [46]. Therefore, the criteria measures the GHG emission reductions of different partner combinations under the same conditions.

(3) Volatile organic compounds (VOCs) (C11): Measures the VOCs emissions from warehouse activities, packing of all mail orders, transportation activities and so on. Since 2015 China has fined enterprises which emit VOCs [52].

(4) Environmental equipment and facilities (C12): Measures the number of orders which are completed by environmental equipment and facilities.

\subsection{Flexibility Criteria}

The sub-criteria affiliated with flexibility criteria for partner combination selection of JDA are summarized as follows:

(1) Types of logistics services (C13): In general, this refers to the coverage of customer demand for online shopping logistics services. Nowadays, the online shopping logistics mode is shifting from cost-centralized to customer-centralized. The more types of logistics services, the greater coverage of customer demand [6].

(2) Diversity of terminal delivery modes (C14): Terminal delivery modes include site self-service, mobile self-service, intelligent terminal self-service delivery and home delivery. This is aimed at satisfying the customer's personalized demand of the last-mile delivery [17,47].

(3) Types of value-added services (C15): Other than logistics services, some value-added services such as payment collection, product's package and labeling are offered. 


\section{The Integrated Fuzzy EW-AHP and TOPSIS Method for Partner Combination Selection}

Usually, the criteria weights are determined according to expert opinion, and this may cause a subjective bias [45]. In this paper, we develop a method of integrating fuzzy EW-AHP method under uncertainty. The key advantage of our method is that, by adopting the fuzzy EW method, we can objectively determine the weight of the criteria on the basis of the criteria evaluating only, and by adopting the AHP method we can comprehensively take the subjective attributes into consideration. In addition, the fuzzy TOPSIS method has been applied in many fields, which shows good performance in the decision-making of alternatives selection $[25,46]$. Therefore, we employ the integrated fuzzy EW-AHP and TOPSIS methods to select the optimal partner combination in this paper.

\subsection{Fuzzy Set Theory}

Fuzzy set theory was proposed by Zadeh [53], which can solve the issues with uncertainty. A fuzzy set $\tilde{a}$ is a pair $(U, m)$ where $U$ is a set and $m: U \rightarrow[0,1]$ is the membership function, provided by $\mu_{\tilde{a}}(x)$. Each element $x$ can be mapped to a real number in the interval $[0,1]$.

A triangular fuzzy number can be represented as a triplet $\tilde{a}=\left[a^{L}, a^{M}, a^{R}\right]$, and its membership function $\mu_{\widetilde{a}}(x)$ is expressed as follows:

$$
\mu_{\tilde{a}}=\left\{\begin{array}{lc}
0 & x<a^{L} \\
\frac{x-a^{L}}{a^{M}-a^{L}} & a^{L} \leqslant x<a^{M} \\
\frac{a^{R}-x}{a^{R}-a^{M}} & a^{M} \leqslant x<a^{R} \\
0 & x>a^{R}
\end{array}\right.
$$

where $a^{L}, a^{M}$ and $a^{R}$ are crisp numbers $\left(-\infty<a^{L} \leqslant a^{M} \leqslant a^{R}<+\infty\right) ; a^{L}$ and $a^{R}$ are the lower and upper bounds of available area for evaluation data, respectively. In order to transform the linguistic variables of decision makers and experts into triangular fuzzy numbers, the transformation rules need be set firstly, as are seen in Tables 1 and 2 [18].

Table 1. Transformation rules of linguistic ratings of decision makers for criteria weight.

\begin{tabular}{cc}
\hline Linguistic Term & Fuzzy Number \\
\hline Of little important (LI) & $(1,1,3)$ \\
Moderately important (MI) & $(1,3,5)$ \\
Important (I) & $(3,5,7)$ \\
Very important (VI) & $(5,7,9)$ \\
Absolutely important (AI) & $(7,9,9)$ \\
\hline
\end{tabular}

Table 2. Transformation rules of linguistic ratings of experts for criteria combination performance of partner combinations.

\begin{tabular}{cc}
\hline Linguistic Term & Fuzzy Number \\
\hline Very low (VL) & $(1,1,3)$ \\
Low (L) & $(1,3,5)$ \\
Medium (M) & $(3,5,7)$ \\
High (H) & $(5,7,9)$ \\
Very high (VH) & $(7,9,9)$ \\
\hline
\end{tabular}

\subsection{Integrated Fuzzy EW-AHP for Determining Criteria Weights}

There are many methods to determine the criteria weights, such as expert opinion survey method or AHP, but these methods have very large subjective factors when determining the criteria [42]. 
Therefore, we will introduce an objective entropy-based criterion that allows decision-makers to assess the informativeness of criteria provided by different experts [45,54-56]. This paper adopts integrated entropy weight method and AHP method to determine the criteria weights taking subjective and objective factors into consideration from different experts. The specific steps of fuzzy EW-AHP methods are as described below.

Step 1: Let $\tilde{r}_{j k}=\left(r_{j k}^{L}, r_{j k}^{M}, r_{j k}^{R}\right), j=1,2, \cdots n, k=1,2, \cdots, r$ be the superiority linguistic rating on criteria weight assigned to criteria $C_{j}$ by decision-maker $D_{k}$. Assume that $\widetilde{s}_{j k}$ is the converted value via $\tilde{r}_{j k}$. Then the fuzzy entropy $\widetilde{e}_{j}$ can be calculated by:

$$
\begin{gathered}
\widetilde{s}_{j k}=\frac{\widetilde{r}_{j k}}{\sum_{k=1}^{r} \widetilde{r}_{j k}} \\
\widetilde{e}_{j}=-\frac{1}{\ln r} \sum_{k=1}^{r} \widetilde{s}_{j k} \ln \widetilde{s}_{j k}
\end{gathered}
$$

Step 2: Calculate the fuzzy EW $\widetilde{w}_{j}^{1}$

$$
\widetilde{w}_{j}^{1}=\frac{1-\widetilde{e}_{j}}{n-\sum_{j=1}^{n} \widetilde{e}_{j}}
$$

Step 3: Calculate the criteria weight $\widetilde{w}_{j}^{2}$ using the fuzzy AHP considering the subjective factors. Details of calculation process of fuzzy AHP method can be referred to the study of Felix et al. [25].

Step 4: Calculate the final weight $\widetilde{w}_{j}$ by integrating the fuzzy EW and fuzzy AHP

$$
\widetilde{w}_{j}=\frac{\widetilde{w}_{j}^{1} \otimes \widetilde{w}_{j}^{2}}{\sum_{j=1}^{n} \widetilde{w}_{j}^{1} \otimes \widetilde{w}_{j}^{2}}
$$

where $\widetilde{w}_{j}=\left(w_{j}^{L}, w_{j}^{M}, w_{j}^{R}\right)$.

\subsection{Fuzzy TOPSIS Method}

TOPSIS is a widely used MCMD method, based on the concept that the best alternative should have the shortest distance from the positive ideal solution and longest distance from the negative ideal solution $[57,58]$. The elements in the decision matrix are expressed by triangular fuzzy number for fuzzy TOPSIS method which is a better way to characterize the practical issues with uncertainty $[59,60]$. The specific steps of fuzzy TOPSIS method are as follows:

Step 1: Calculate the aggregate fuzzy linguistic ratings for combination performance of alternatives.

Let us consider a set of $m$ alternatives (partner combinations) $A=\left\{A_{1}, A_{2}, \cdots, A_{m}\right\}$ which are to be evaluated against a set of $n$ criteria $C=\left\{C_{1}, C_{2}, \cdots, C_{n}\right\}$. The combination performances of $n$ criteria are defined in linguistic terms that can be obtained from experts. Let $\tilde{a}_{i j k}=\left(a_{i j k}^{L}, a_{i j k}^{M}, a_{i j k}^{R}\right)$, $0 \leqslant a_{i j k}^{L} \leqslant a_{i j k}^{M} \leqslant a_{i j k}^{R} \leqslant 1$ be combination performance linguistic rating of expert $D_{k}(k=1,2, \cdots, r)$ for each alternative $A_{i}(i=1,2, \cdots, m)$ with respect to criteria $C_{j}(j=1,2, \cdots, n)$. Then the fuzzy linguistic rating $\tilde{a}_{i j}=\left(a_{i j}^{L}, a_{i j}^{M}, a_{i j}^{R}\right), a_{i j}^{L}=\sum_{k=1}^{r} \frac{a_{i j k}^{L}}{r}, a_{i j}^{M}=\sum_{k=1}^{r} \frac{a_{i j k}^{M}}{r}, a_{i j}^{R}=\sum_{k=1}^{r} \frac{a_{i j k}^{R}}{r}$ for criteria $C_{j}$ of alternative $A_{i}$ can be calculated by:

$$
\tilde{a}_{i j}=(1 / r) \otimes\left(\tilde{a}_{i j 1} \oplus \tilde{a}_{i j 2}, \cdots, \oplus \tilde{a}_{i j r}\right)
$$

Step 2: Build the initial fuzzy decision matrix.

According to Equation (6), the initial fuzzy decision matrix $A$ can be built. 


$$
A=\left(\widetilde{a}_{i j}\right)=\left[\begin{array}{ccc}
\tilde{a}_{11} & \ldots & \tilde{a}_{1 n} \\
\vdots & \ddots & \vdots \\
\tilde{a}_{m 1} & \ldots & \tilde{a}_{m n}
\end{array}\right]=\left[\begin{array}{ccc}
\left(a_{11}^{L}, a_{11}^{M}, a_{11}^{R}\right) & \ldots & \left(a_{1 n}^{L}, a_{1 n}^{M}, a_{1 n}^{R}\right) \\
\vdots & \ddots & \vdots \\
\left(a_{m 1}^{L}, a_{m 1}^{M}, a_{m 1}^{R}\right) & \ldots & \left(a_{m n}^{L}, a_{m n}^{M}, a_{m n}^{R}\right)
\end{array}\right]
$$

Step 3: Normalize the fuzzy decision matrix.

In general, there are two kinds of attributes namely benefit-type and cost-type in the criteria. For the benefit-type criteria, the larger the better, such as resource complementarity; for the cost-type criteria, the smaller the better, such logistics cost. Therefore, the normalization processing on the different kinds of criteria needs to be first performed $[18,61]$.

For benefit-type criteria, the normalization processing is expressed as:

$$
\tilde{b}_{i j}=\frac{\tilde{a}_{i j}-\operatorname{Min}\left\{\tilde{a}_{i j}, i=1,2, \cdots, m\right\}}{\operatorname{Max}\left\{\tilde{a}_{i j}, i=1,2, \cdots, m\right\}-\operatorname{Min}\left\{\tilde{a}_{i j}, i=1,2, \cdots, m\right\}} \forall j=1,2, \cdots, n
$$

For cost-type criteria, the normalization processing is expressed as:

$$
\widetilde{b}_{i j}=\frac{\operatorname{Max}\left\{\tilde{a}_{i j}, i=1,2, \cdots, m\right\}-\tilde{a}_{i j}}{\operatorname{Max}\left\{\tilde{a}_{i j}, i=1,2, \cdots, m\right\}-\operatorname{Min}\left\{\widetilde{a}_{i j}, i=1,2, \cdots, m\right\}} \forall j=1,2, \cdots, n
$$

Then, the normalized fuzzy decision matrix $B$ can be obtained as:

$$
B=\left(\widetilde{b}_{i j}\right)_{m^{*} n}=\left[\begin{array}{ccc}
\widetilde{b}_{11} & \ldots & \tilde{a}_{1 n} \\
\vdots & \ddots & \vdots \\
\widetilde{a}_{m 1} & \cdots & \widetilde{a}_{m n}
\end{array}\right]=\left[\begin{array}{ccc}
\left(b_{11}^{L}, b_{11}^{M}, b_{11}^{R}\right) & \ldots & \left(b_{1 n}^{L}, b_{1 n}^{M}, b_{1 n}^{R}\right) \\
\vdots & \ddots & \vdots \\
\left(b_{m 1}^{L}, b_{m 1}^{M}, b_{m 1}^{R}\right) & \cdots & \left(b_{m n}^{L}, b_{m n}^{M}, b_{m n}^{R}\right)
\end{array}\right]
$$

Step 4: Determine the integrated fuzzy weights of criteria.

The integrated fuzzy weight of criteria $\widetilde{w}_{j}$ can be calculated using Equations (2)-(5).

Step 5: Calculate the weight normalized fuzzy decision matrix.

The weight normalized fuzzy decision matrix $C$ can be calculated using Equation (11).

$$
C=\left(\widetilde{c}_{i j}\right)_{m * n}=\left[\begin{array}{ccc}
\widetilde{w}_{1} \otimes \widetilde{b}_{11} & \ldots & \widetilde{w}_{n} \otimes \widetilde{b}_{1 n} \\
\vdots & \ddots & \vdots \\
\widetilde{w}_{1} \otimes \widetilde{b}_{m 1} & \cdots & \widetilde{w}_{n} \otimes \widetilde{b}_{m n}
\end{array}\right]=\left[\begin{array}{ccc}
\left(w_{1}^{L} b_{11}^{L}, w_{1}^{M} b_{11}^{M}, w_{1}^{R} b_{11}^{R}\right) & \ldots & \left(w_{n}^{L} b_{1 n}^{L}, w_{n}^{M} b_{1 n^{M}}^{M}, w_{n}^{R} b_{1 n}^{R}\right) \\
\vdots & \ddots & \vdots \\
\left(w_{1}^{L} b_{m 1}^{L}, w_{1}^{M} b_{m 1}^{M}, w_{1}^{R} b_{m 1}^{R}\right) & \cdots & \left(w_{n}^{L} b_{m n}^{L}, w_{n}^{M} b_{m n}^{M}, w_{n}^{R} b_{m n}^{R}\right)
\end{array}\right]
$$

Step 6: Calculate the distances of the alternatives from the fuzzy positive and negative ideal solution. Step 6.1: Determine the fuzzy positive ideal solution and negative ideal solution.

Suppose that $J_{1}$ and $J_{2}$ respectively represent the benefit-type criteria set and cost-type criteria set. $C^{+}$ and $C^{-}$represent the fuzzy positive ideal solution and negative ideal solution, respectively. Then, $C^{+}$ and $\mathrm{C}^{-}$can be calculated by

$$
\begin{aligned}
& C^{+}=\left(c_{j}^{+L}, c_{j}^{+M}, c_{j}^{+R}\right)=\left\{\left(\max _{i} c_{i j} \mid j \in J_{1}\right),\left(\min _{i} c_{i j} \mid j \in J_{2}\right)\right\} \\
& C^{-}=\left(c_{j}^{-L}, c_{j}^{-M}, c_{j}^{-R}\right)=\left\{\left(\min _{i} c_{i j} \mid j \in J_{1}\right),\left(\max _{i} c_{i j} \mid j \in J_{2}\right)\right\}
\end{aligned}
$$

where

$$
\begin{aligned}
\max _{i} c_{i j} & =\left(\max _{i} w_{j}^{L} b_{i j}^{L}, \max _{i} w_{j}^{M} b_{i j}^{M}, \max _{i} w_{j}^{R} b_{i j}^{R}\right) \\
\min _{i} c_{i j} & =\left(\min _{i} w_{j}^{L} b_{i j}^{L}, \min _{i} w_{j}^{M} b_{i j}^{M}, \min _{i} w_{j}^{R} b_{i j}^{R}\right)
\end{aligned}
$$


Step 6.2: Calculate the distances.

In this paper, a modified geometrical distance method is employed which can reflect more information of experts with uncertainty than the Euclidean distance [62]. The distance $d(\tilde{a}, \tilde{b})$ between two triangular fuzzy numbers $\tilde{a}$ and $\tilde{b}$ can be calculated by

$$
d(\tilde{a}, \widetilde{b})=\frac{\left|a^{L}-b^{L}\right|+\left|a^{M}-b^{M}\right|+\left|a^{R}-b^{R}\right|+\left|\pi_{\tilde{a}}-\pi_{\tilde{b}}\right|}{3}
$$

where $\pi_{\widetilde{a}}$ and $\pi_{\widetilde{b}}$ are the uncertainty degree of the two triangular fuzzy numbers $\tilde{a}$ and $\tilde{b}$, and $\pi_{\widetilde{a}}=a^{R}-a^{L}, \pi_{\widetilde{b}}=b^{R}-b^{L}$.

Therefore, the distance $\left(d_{i}^{+}, d_{i}^{-}\right)$of alternative $i$ from the fuzzy positive and negative ideal solution can be calculated by

$$
\begin{aligned}
& d_{i}^{+}=\frac{\sum_{j=1}^{n}\left(\left|c_{i j}^{L}-c_{j}^{+L}\right|+\left|c_{i j}^{M}-c_{j}^{+M}\right|+\left|c_{i j}^{R}-c_{j}^{+R}\right|+\left|\pi_{\widetilde{c}_{i j}}-\pi_{\widetilde{c}_{j}}\right|\right)}{3 n} \\
& d_{i}^{+}=\frac{\sum_{j=1}^{n}\left(\left|c_{i j}^{L}-c_{j}^{-L}\right|+\left|c_{i j}^{M}-c_{j}^{-M}\right|+\left|c_{i j}^{R}-c_{j}^{-R}\right|+\left|\pi_{\widetilde{c}_{i j}}-\pi_{\widetilde{c}_{j}}\right|\right)}{3 n}
\end{aligned}
$$

Step 7: Calculate the relative closeness of alternative $A_{i}$ to the ideal solution $A^{*}$

$$
R C_{i}=\frac{d_{i}^{-}}{d_{i}^{-}+d_{i}^{+}}, \quad 0 \leqslant R C_{i} \leqslant 1
$$

Step 8: Rank the alternatives on the basis of relative closeness to the ideal solution.

According to the calculation results in Step 7, the alternative with the greatest $R C_{i}$ to the ideal solution should be selected as the optimal partner combination.

\subsection{Sensitivity Analysis}

Sensitivity analysis is to test the robustness of a proposed method, and the influence of criteria weight changes on the results. In order to assess the influence of criteria weights on the rankings of the four alternatives, four set of cases are performed where:

(1) The sub-criteria has 5\%, 10\%, 20\% less weight and 5\%, 10\%, 20\% more weight than the base weight (i.e., the weight obtained in Section 3.2.) in economy criteria.

(2) The sub-criteria has 5\%,10\%, 20\% less weight and 5\%,10\%, 20\% more weight than the base weight in society criteria.

(3) The sub-criteria has 5\%,10\%, 20\% less weight and 5\%, 10\%, 20\% more weight than the base weight in environment criteria.

(4) The sub-criteria has 5\%, 10\%, 20\% less weight and 5\%, 10\%, 20\% more weight than the base weight in flexibility criteria.

The rankings of the alternatives are evaluated for each of these cases and the influence of changes in criteria weights on optimal alternative is assessed.

The framework of the integrated fuzzy EW-AHP and TOPSIS method for partner combination evaluation of JDA is shown in Figure 2. 


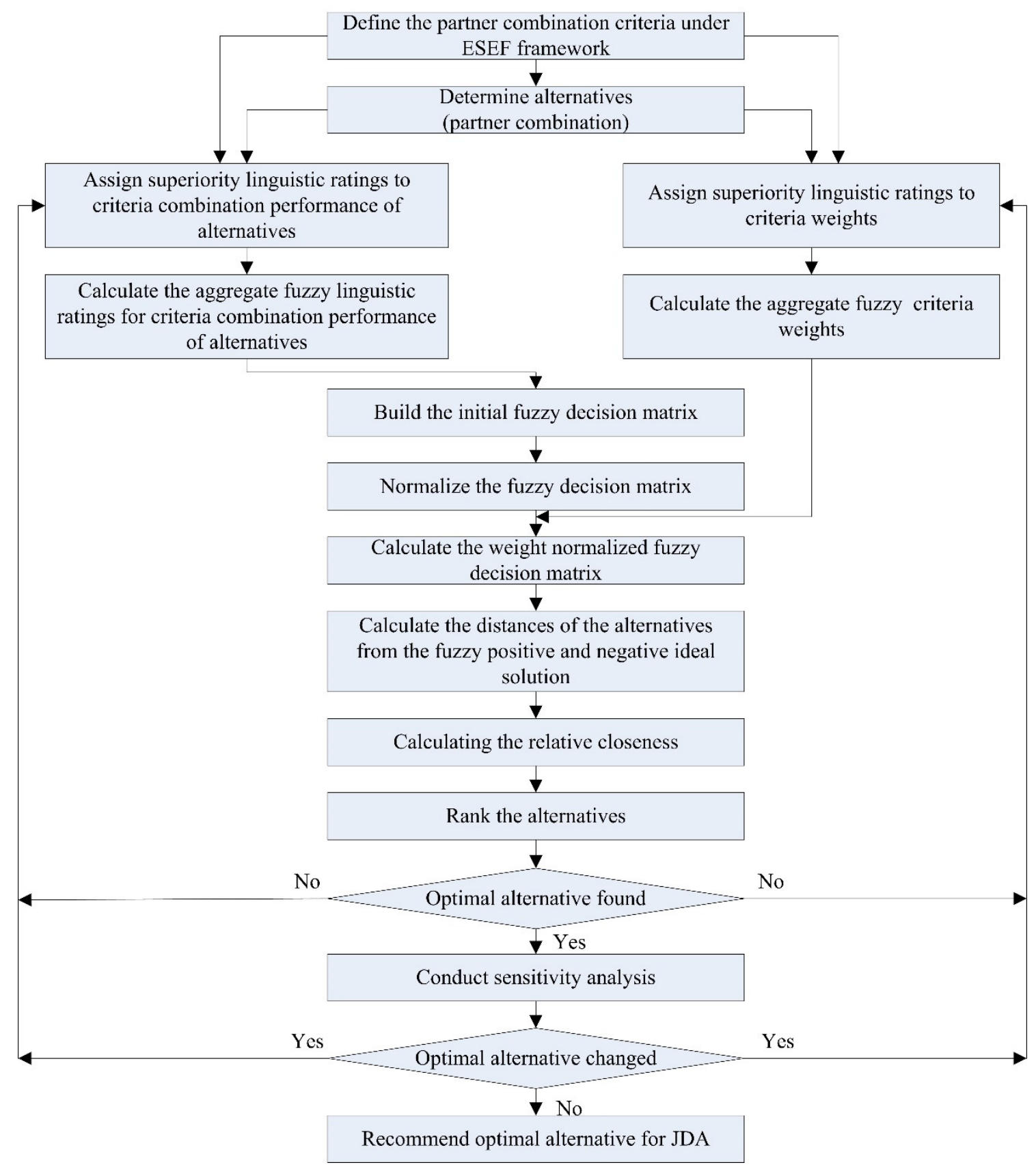

Figure 2. Calculation framework of the integrated fuzzy EW-AHP and TOPSIS method for partner combination evaluation of JDA.

\section{Numerical Application}

This section presents an application of the proposed method to select the optimal partner combination consisting of alternative partners. Let us consider an express logistics enterprise CQ (all enterprises' names are abbreviated for anonymity in this paper) interested in evaluating four alternative partners namely RC, RK (two main transportation enterprises) and ML, BH (two end distribution enterprises). In order to achieve operational efficiency and service customers better using online shopping, CQ is going to select one of two main transportation enterprises (RC and RK) and one of two end distribution enterprises $(\mathrm{ML}$ and $\mathrm{BH})$ in his distribution area. Therefore, there are four partner combinations $P C_{1}$ (including $C Q, R C$ and $M L$ ), $P C_{2}$ (including $C Q, R C$ and $\mathrm{BH}$ ), $P C_{3}$ (including $\mathrm{CQ}$, $\mathrm{RK}$ and $\mathrm{ML}$ ), $\mathrm{PC}_{4}$ (including $\mathrm{CQ}, \mathrm{RK}$ and $\mathrm{BH}$ ). The main procedures are as follows: 
Step 1: The linguistic ratings for criteria weights and partner combination performance are obtained according to expert opinion.

In order to obtain the linguistic ratings, five groups of expert panels $(k=1,2, \cdots, 5)$ in the fields of economy, environment, society, logistics, and e-commerce were formed. Each group of expert panel gave the linguistic ratings judgments for the criteria weights and combination performance of each alternative, as can be seen in Tables 3 and 4 .

Table 3. Linguistic ratings for criteria weights.

\begin{tabular}{cccccccccccccccc}
\hline & C1 & C2 & C3 & C4 & C5 & C6 & C7 & C8 & C9 & C10 & C11 & C12 & C13 & C14 & C15 \\
\hline EP1 & AI & VI & AI & VI & I & AI & I & AI & AI & AI & AI & AI & AI & AI & AI \\
EP2 & AI & I & VI & I & VI & VI & MI & AI & VI & VI & AI & VI & AI & AI & VI \\
EP3 & VI & I & VI & I & I & VI & VI & AI & AI & VI & VI & AI & AI & VI & I \\
EP4 & VI & MI & AI & MI & I & AI & I & VI & AI & I & V & VI & AI & AI & I \\
EP5 & AI & I & VI & MI & VI & AI & I & I & VI & I & VI & AI & VI & VI & VI \\
\hline \multicolumn{7}{c}{ Note: EP1, EP2, EP3, EP4 and EP5 represent the five groups of expert panels respectively. }
\end{tabular}

Table 4. Linguistic ratings for partner combination performance for each criteria.

\begin{tabular}{|c|c|c|c|c|c|c|c|c|c|c|c|c|c|c|c|c|}
\hline & & C1 & C2 & C3 & C4 & C5 & C6 & C7 & C8 & C9 & C10 & C11 & C12 & C13 & C14 & C15 \\
\hline \multirow{4}{*}{ EP1 } & PC1 & $\mathrm{VH}$ & $\mathrm{VH}$ & $\mathrm{H}$ & $\mathrm{H}$ & $\mathrm{H}$ & $\mathrm{M}$ & $\mathrm{M}$ & $\mathrm{M}$ & L & $\mathrm{M}$ & $\mathrm{VH}$ & $\mathrm{H}$ & $\mathrm{M}$ & $\mathrm{H}$ & $\mathrm{M}$ \\
\hline & PC2 & $\mathrm{H}$ & $\mathrm{VH}$ & $\mathrm{H}$ & $\mathrm{M}$ & $\mathrm{H}$ & $\mathrm{M}$ & $\mathrm{M}$ & $\mathrm{M}$ & VL & $\mathrm{L}$ & $\mathrm{L}$ & $\mathrm{M}$ & $\mathrm{H}$ & $\mathrm{M}$ & $\mathrm{H}$ \\
\hline & PC3 & $\mathrm{H}$ & $\mathrm{VH}$ & M & $\mathrm{H}$ & $\mathrm{VH}$ & $\mathrm{VH}$ & $\mathrm{H}$ & $\mathrm{VH}$ & $\mathrm{VH}$ & $\mathrm{VH}$ & $\mathrm{VH}$ & $\mathrm{H}$ & $\mathrm{VH}$ & $\mathrm{VH}$ & VH \\
\hline & PC4 & $\mathrm{VH}$ & $\mathrm{H}$ & $\mathrm{M}$ & $\mathrm{H}$ & $\mathrm{H}$ & $\mathrm{M}$ & $\mathrm{M}$ & $\mathrm{VH}$ & $\mathrm{VH}$ & $\mathrm{H}$ & $\mathrm{H}$ & $\mathrm{M}$ & $\mathrm{M}$ & $\mathrm{H}$ & $\mathrm{H}$ \\
\hline \multirow{4}{*}{ EP2 } & PC1 & $\mathrm{H}$ & $\mathrm{H}$ & $\mathrm{VH}$ & $\mathrm{H}$ & $\mathrm{H}$ & $\mathrm{M}$ & $\mathrm{M}$ & $\mathrm{M}$ & $\mathrm{L}$ & M & $\mathrm{H}$ & $\mathrm{M}$ & $\mathrm{M}$ & $\mathrm{H}$ & $\mathrm{H}$ \\
\hline & PC2 & $\mathrm{H}$ & $\mathrm{M}$ & $\mathrm{M}$ & $\mathrm{H}$ & $\mathrm{H}$ & $\mathrm{M}$ & $\mathrm{M}$ & L & L & $\mathrm{M}$ & L & $\mathrm{M}$ & $\mathrm{H}$ & $\mathrm{M}$ & $\mathrm{H}$ \\
\hline & PC3 & $\mathrm{VH}$ & $\mathrm{H}$ & $\mathrm{H}$ & VH & $\mathrm{H}$ & $\mathrm{VH}$ & $\mathrm{VH}$ & $\mathrm{VH}$ & $\mathrm{H}$ & VH & $\mathrm{H}$ & VH & $\mathrm{VH}$ & $\mathrm{M}$ & $\mathrm{VH}$ \\
\hline & PC4 & $\mathrm{H}$ & $\mathrm{H}$ & M & $\mathrm{H}$ & $\mathrm{H}$ & $\mathrm{M}$ & $\mathrm{H}$ & VH & $\mathrm{H}$ & $\mathrm{VH}$ & $\mathrm{H}$ & $\mathrm{H}$ & $\mathrm{M}$ & $\mathrm{M}$ & $\mathrm{H}$ \\
\hline \multirow{4}{*}{ EP3 } & PC1 & $\mathrm{H}$ & $\mathrm{VH}$ & $\mathrm{H}$ & $\mathrm{M}$ & $\mathrm{M}$ & $\mathrm{H}$ & L & $\mathrm{M}$ & $\mathrm{M}$ & $\mathrm{L}$ & $\mathrm{H}$ & $\mathrm{H}$ & $\mathrm{M}$ & $\mathrm{H}$ & $\mathrm{VH}$ \\
\hline & PC2 & $\mathrm{M}$ & $\mathrm{H}$ & $\mathrm{H}$ & $\mathrm{M}$ & $\mathrm{H}$ & $\mathrm{M}$ & $\mathrm{H}$ & L & $\mathrm{M}$ & $\mathrm{M}$ & $\mathrm{M}$ & $\mathrm{M}$ & $\mathrm{L}$ & $\mathrm{H}$ & $\mathrm{M}$ \\
\hline & PC3 & $\mathrm{VH}$ & $\mathrm{VH}$ & $\mathrm{H}$ & $\mathrm{H}$ & $\mathrm{VH}$ & $\mathrm{H}$ & $\mathrm{H}$ & VH & VH & $\mathrm{H}$ & $\mathrm{VH}$ & $\mathrm{VH}$ & $\mathrm{VH}$ & $\mathrm{VH}$ & $\mathrm{H}$ \\
\hline & PC4 & $\mathrm{H}$ & $\mathrm{M}$ & $\mathrm{H}$ & $\mathrm{H}$ & $\mathrm{H}$ & $\mathrm{H}$ & $\mathrm{M}$ & $\mathrm{H}$ & $\mathrm{VH}$ & $\mathrm{VH}$ & $\mathrm{H}$ & $\mathrm{M}$ & $\mathrm{H}$ & $\mathrm{H}$ & $\mathrm{H}$ \\
\hline \multirow{4}{*}{ EP4 } & PC1 & $\mathrm{H}$ & $\mathrm{H}$ & $\mathrm{VH}$ & $\mathrm{M}$ & $\mathrm{M}$ & L & $\mathrm{M}$ & $\mathrm{M}$ & L & $\mathrm{M}$ & $\mathrm{VH}$ & $\mathrm{H}$ & $\mathrm{H}$ & $\mathrm{H}$ & $\mathrm{M}$ \\
\hline & PC2 & M & $\mathrm{H}$ & $\mathrm{M}$ & $\mathrm{M}$ & $\mathrm{H}$ & $\mathrm{H}$ & $\mathrm{VH}$ & $\mathrm{L}$ & $\mathrm{M}$ & $\mathrm{L}$ & $\mathrm{M}$ & $\mathrm{M}$ & $\mathrm{H}$ & $\mathrm{H}$ & M \\
\hline & PC3 & $\mathrm{H}$ & $\mathrm{VH}$ & $\mathrm{VH}$ & VH & $\mathrm{VH}$ & VH & $\mathrm{VH}$ & $\mathrm{H}$ & $\mathrm{H}$ & $\mathrm{VH}$ & $\mathrm{VH}$ & $\mathrm{H}$ & $\mathrm{VH}$ & $\mathrm{H}$ & $\mathrm{VH}$ \\
\hline & PC4 & $\mathrm{H}$ & $\mathrm{VH}$ & $\mathrm{M}$ & $\mathrm{M}$ & $\mathrm{H}$ & $\mathrm{H}$ & $\mathrm{H}$ & $\mathrm{VH}$ & $\mathrm{H}$ & $\mathrm{H}$ & $\mathrm{H}$ & $\mathrm{H}$ & $\mathrm{M}$ & $\mathrm{M}$ & $\mathrm{H}$ \\
\hline \multirow{4}{*}{ EP5 } & PC1 & $\mathrm{H}$ & $\mathrm{M}$ & $\mathrm{H}$ & $\mathrm{H}$ & $\mathrm{H}$ & $\mathrm{M}$ & $\mathrm{M}$ & $\mathrm{M}$ & L & VL & VH & $\mathrm{H}$ & $\mathrm{M}$ & M & $\mathrm{H}$ \\
\hline & PC2 & $\mathrm{M}$ & $\mathrm{H}$ & $\mathrm{H}$ & $\mathrm{VH}$ & $\mathrm{H}$ & $\mathrm{VH}$ & $\mathrm{M}$ & $\mathrm{L}$ & $\mathrm{H}$ & $\mathrm{M}$ & $\mathrm{M}$ & $\mathrm{H}$ & $\mathrm{M}$ & $\mathrm{H}$ & $\mathrm{VH}$ \\
\hline & PC3 & $\mathrm{VH}$ & $\mathrm{VH}$ & $\mathrm{H}$ & $\mathrm{H}$ & $\mathrm{H}$ & $\mathrm{VH}$ & $\mathrm{VH}$ & $\mathrm{VH}$ & $\mathrm{H}$ & $\mathrm{VH}$ & $\mathrm{H}$ & VH & $\mathrm{VH}$ & $\mathrm{H}$ & $\mathrm{VH}$ \\
\hline & PC4 & $\mathrm{H}$ & $\mathrm{H}$ & $\mathrm{M}$ & $\mathrm{H}$ & $\mathrm{H}$ & $\mathrm{VH}$ & $\mathrm{H}$ & VH & $\mathrm{VH}$ & $\mathrm{H}$ & $\mathrm{H}$ & $\mathrm{M}$ & $\mathrm{H}$ & $\mathrm{M}$ & $\mathrm{M}$ \\
\hline
\end{tabular}

Step 2: According to Table 3 and Equations (2)-(5), the integrated weights of criteria can be calculated and the results are seen in Table 5.

Step 3: According to Table 2 and Equations (6) and (7), the initial fuzzy decision matrix $A$ can be obtained:

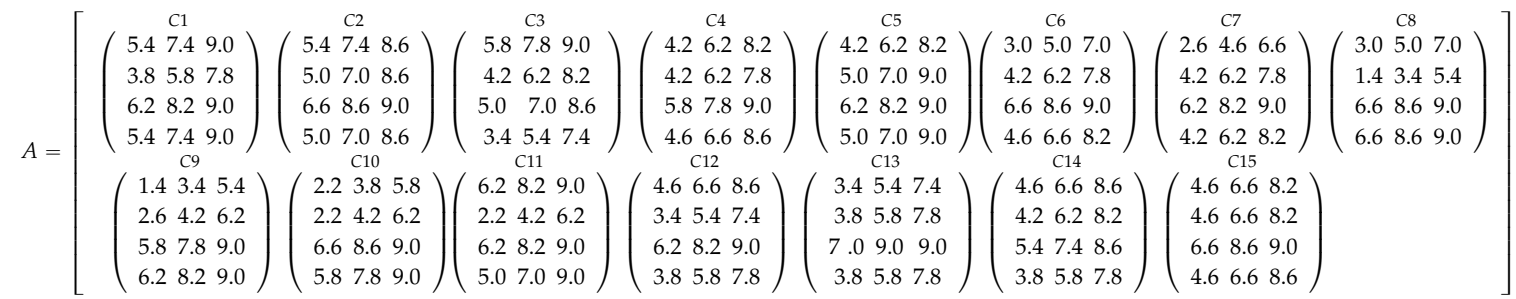


Table 5. Integrated weights of criteria.

\begin{tabular}{|c|c|c|c|c|c|}
\hline Fuzzy-EW & $\begin{array}{c}\mathrm{C} 1 \\
{[0.023,0.025,0.032]} \\
\mathrm{C} 6 \\
{[0.023,0.025,0.036]} \\
\mathrm{C} 11 \\
{[0.025,0.026,0.036]}\end{array}$ & $\begin{array}{c}C 2 \\
{[0.116,0.144,0.146]} \\
C 7 \\
{[0.116,0.144,0.0148]} \\
C 12 \\
{[0.021,0.024,0.037]}\end{array}$ & $\begin{array}{c}\mathrm{C} 3 \\
{[0.025,0.025,0.036]} \\
\mathrm{C} 8 \\
{[0.058,0.066,0.083]} \\
\mathrm{C} 13 \\
{[0.016,0.025,0.025]}\end{array}$ & $\begin{array}{c}\mathrm{C} 4 \\
{[0.178,0.211,0.250]} \\
\mathrm{C} 9 \\
{[0.023,0.026,0.034]} \\
\mathrm{C} 14 \\
{[0.024,0.025,0.034]}\end{array}$ & $\begin{array}{c}\mathrm{C} 5 \\
{[0.052,0.056,0.082]} \\
\mathrm{C} 10 \\
{[0.078,0.080,0.092]} \\
\mathrm{C} 15 \\
{[0.079,0.080,0.091]}\end{array}$ \\
\hline Fuzzy-AHP & $\begin{array}{c}\mathrm{C} 1 \\
{[0.073,0.078,0.082]} \\
\mathrm{C} 6 \\
{[0.074,0.079,0.082]} \\
\mathrm{C} 11 \\
{[0.058,0.061,0.063]}\end{array}$ & $\begin{array}{c}\mathrm{C} 2 \\
{[0.040,0.048,0.057]} \\
\mathrm{C} 7 \\
{[0.040,0.047,0.058]} \\
\mathrm{C} 12 \\
{[0.073,0.078,0.082]}\end{array}$ & $\begin{array}{c}\mathrm{C} 3 \\
{[0.073,0.074,0.077]} \\
\mathrm{C} 8 \\
{[0.070,0.075,0.076]} \\
\mathrm{C} 13 \\
{[0.072,0.082,0.087]}\end{array}$ & $\begin{array}{c}\mathrm{C} 4 \\
{[0.034,0.044,0.053]} \\
\mathrm{C} 9 \\
{[0.073,0.080,0.082]} \\
\mathrm{C} 14 \\
{[0.073,0.078 ; 0.082]}\end{array}$ & $\begin{array}{c}\mathrm{C} 5 \\
{[0.050,0.055,0.063]} \\
\mathrm{C} 10 \\
{[0.060,0.063,0.066]} \\
\mathrm{C} 15 \\
{[0.062,0.063,0.066]}\end{array}$ \\
\hline $\begin{array}{l}\text { Integrated } \\
\text { weights }\end{array}$ & $\begin{array}{c}\mathrm{C} 1 \\
{[0.030,0.037,0.045]} \\
\mathrm{C} 6 \\
{[0.030,0.033,0.045]} \\
\mathrm{C} 11 \\
{[0.024,0.031,0.036]}\end{array}$ & $\begin{array}{c}C 2 \\
{[0.092,0.110,0.134]} \\
C 7 \\
{[0.092,0.113,0.133]} \\
C 12 \\
{[0.030,0.036,0.044]}\end{array}$ & $\begin{array}{c}\mathrm{C} 3 \\
{[0.030,0.037,0.044]} \\
\mathrm{C} 8 \\
{[0.066,0.097,0.103]} \\
\mathrm{C} 13 \\
{[0.027,0.030,0.035]}\end{array}$ & $\begin{array}{c}C 4 \\
{[0.130,0.165,0.182]} \\
C 9 \\
{[0.030,0.036,0.045]} \\
C 14 \\
{[0.031,0.038,0.046]}\end{array}$ & $\begin{array}{c}\mathrm{C} 5 \\
{[0.050,0.051,0.084]} \\
\mathrm{C} 10 \\
{[0.084,0.094,0.096]} \\
\mathrm{C} 15 \\
{[0.084,0.094,0.096]}\end{array}$ \\
\hline
\end{tabular}

Step 4: The weighted normalized fuzzy decision matrix is calculated using Equations (8)-(11).

Among the fifteen criteria, C1, C3, C5, C6, C7, C8, C10, C12, C13, C14 and C15 are benefit-type criteria; $\mathrm{C} 2, \mathrm{C} 4, \mathrm{C} 9$ and $\mathrm{C} 11$ are cost-type criteria. To obtain the normalized fuzzy decision matrix $B$ and weighted normalized fuzzy decision matrix $C$, we use Equations (8)-(11). For example, the benefit-type criteria $\mathrm{C} 1$ is normalized using Equation (8) as follows:

$$
b_{11}^{L}=\frac{5.4-3.8}{6.2-3.8}=0.667, b_{11}^{M}=\frac{7.4-5.8}{8.2-5.8}=0.667, b_{11}^{R}=\frac{9.0-7.8}{9.0-7.8}=1 .
$$

Then $\widetilde{b}_{11}=(0.667,0.667,1)$. Applying Equation (11) for criteria $C 1$, we get $\widetilde{c}_{11}=(0.020,0.025,0.045)$. Here, $\widetilde{b}_{11}$ refers to the combination performance of alternative 1 with respect to criteria 1 in the normalized fuzzy decision matrix, and $\widetilde{c}_{11}$ refers to the combination performance of alternative 1 with respect to criteria 1 in the weight normalized fuzzy decision matrix.

Other elements in weighted normalized fuzzy decision matrix $C$ can be calculated in the same way. Therefore, the weighted normalized fuzzy decision matrix $C$ is obtained as below:

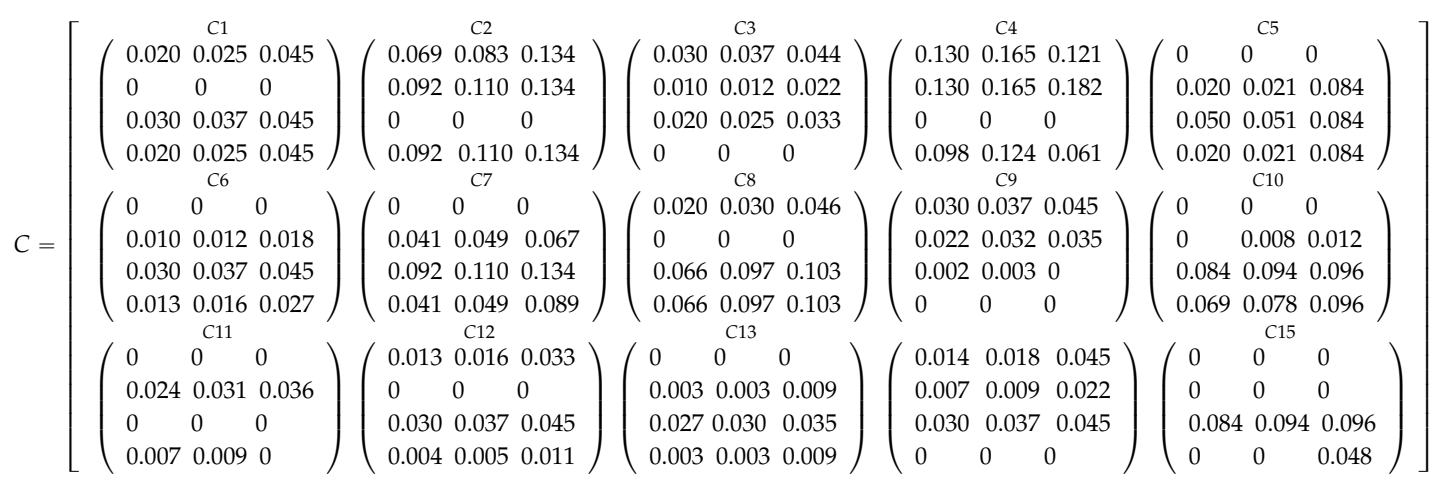

Step 5: The distances of the alternatives from the fuzzy positive and negative ideal solution are calculated.

The fuzzy positive and negative ideal solution can be calculated using Equations (12) and (13), and the distances $d_{i}^{+}$and $d_{i}^{-}$of alternative $i$ from the fuzzy positive and negative ideal solution can be calculated using Equations (14)-(16), i.e.,

$$
d_{1}^{+}=0.0603, d_{2}^{+}=0.0643, d_{3}^{+}=0.0078, d_{4}^{+}=0.0457
$$




$$
d_{1}^{-}=0.0166, d_{2}^{-}=0.0147, d_{3}^{-}=0.0743, d_{4}^{-}=0.0430
$$

Step 6: The relative closeness of alternatives to the ideal solution is calculated.

Finally, the relative closeness of alternative $A_{i}$ to the ideal solution can be calculated using Equation (17):

$$
\begin{gathered}
R C_{1}=\frac{d_{1}^{-}}{d_{1}^{-}+d_{1}^{+}}=0.2164, R C_{2}=\frac{d_{2}^{-}}{d_{2}^{-}+d_{2}^{+}}=0.1862, R C_{3}=\frac{d_{3}^{-}}{d_{3}^{-}+d_{3}^{+}}=0.9045, \\
R C_{4}=\frac{d_{4}^{-}}{d_{4}^{-}+d_{4}^{+}}=0.4850
\end{gathered}
$$

Step 7: On the basis of relative closeness, the four alternatives are ranked as follows:

$$
R C_{3}>R C_{4}>R C_{1}>R C_{2}
$$

It is seen above that the partner combination $P C_{3}$ ranks first, so $P C_{3}$, namely the partner combination $C Q$, RK and ML, should be selected as the optimal alternative.

\section{Discussion}

The partner combinations of JDA are ranked by using integrated fuzzy EW-AHP and TOPSIS method. The result shows that the partner combination $P C_{3}$ is the optimal alternative. In order to test the robustness of decision, a sensitivity analysis is performed in terms of the influence of criteria weight changes on the result.

Figure 3 shows those cases where the economic criteria have $5 \%, 10 \%$ and $20 \%$ less weight and $5 \%$, $10 \%$ and $20 \%$ more weight than the base weight (i.e., the weight used in Section 4). It can be seen that, as the economic criteria become more important, the relative closeness of the partner combinations $P C_{3}$ and $P C_{4}$ decreases slightly. The relative closeness of partner combinations $P C_{1}$ and $P C_{2}$ increases slightly, but the relative closeness of partner combination $P C_{2}$ is far removed from that of partner combination $P C_{1}$. In this case, $P C_{3}$ always has the highest relative closeness. Therefore, no matter how the criteria weights of the economic criteria change, $P C_{3}$ is always the optimal partner combination, which indicates the robustness and effectiveness of the proposed methodology.

Cases where the societal criteria have $5 \%, 10 \%$ and $20 \%$ less weight and $5 \%, 10 \%$ and $20 \%$ more weight than the base weight are shown in Figure 4. It can be seen that, as the societal criteria become more important, the relative closeness of partner combinations $P C_{3}$ and $P C_{4}$ changes with a slight increase. The relative closeness of partner combination $P C_{2}$ gets so far away from that of partner combination $P C_{1}$. However, no matter how the criteria weights of the societal criteria change, $P C_{3}$ is always the optimal partner combination, which indicates the robustness and effectiveness of the proposed methodology.

Figure 5 shows those cases where the environmental criteria have $5 \%, 10 \%$ and $20 \%$ less weight and $5 \%, 10 \%$ and $20 \%$ more weight than the base weigh. It can be seen that the relative closeness of partner combinations $P C_{1}$ and $P C_{2}$ has the same variation trend with a slight decrease in the case of environment criteria fluctuation. Although the relative closeness of partner combinations $P C_{3}$ and $P C_{4}$ have the same variation trend with slight increase, the relative closeness of partner combination $P C_{3}$ increases faster than that of partner combination $P C_{4}$. Therefore, $P C_{3}$ is also the optimal partner combination no matter how the criteria weights of the environmental criteria change, which indicates the robustness and effectiveness of the proposed methodology.

Cases where the flexibility criteria have $5 \%, 10 \%$ and $20 \%$ less weight and $5 \%, 10 \%$ and $20 \%$ more weight than the base weigh are shown in Figure 6. It can be seen that, as the flexibility criteria become more important, the relative closeness of partner combination $P C_{1}$ decreases, and it ranks fourth, surpassed by $P C_{2}$. The relative closeness of partner combination $P C_{4}$ increases, which gets closer to that of alternative $P C_{3}$ (the best alternative). However, the partner combination $P C_{3}$ still ranks first. Therefore, $P C_{3}$ is always the optimal partner combination no matter how the criteria 
weights of the flexibility criteria change, which indicates the robustness and effectiveness of the proposed methodology.

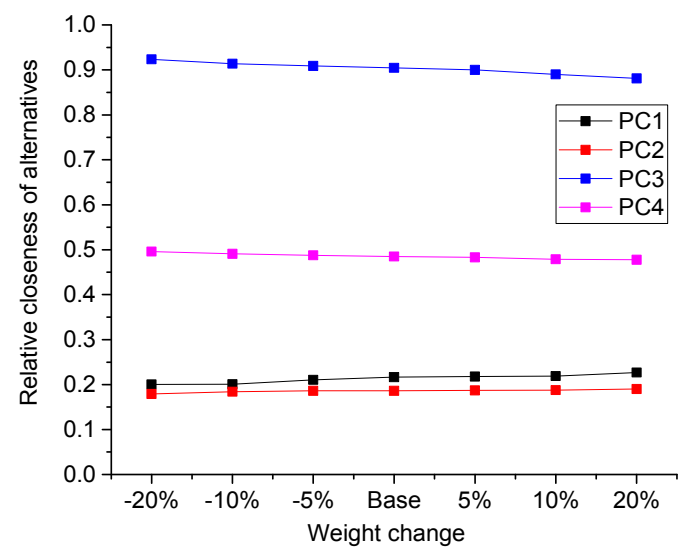

Figure 3. Sensitivity analysis result of economy criteria.

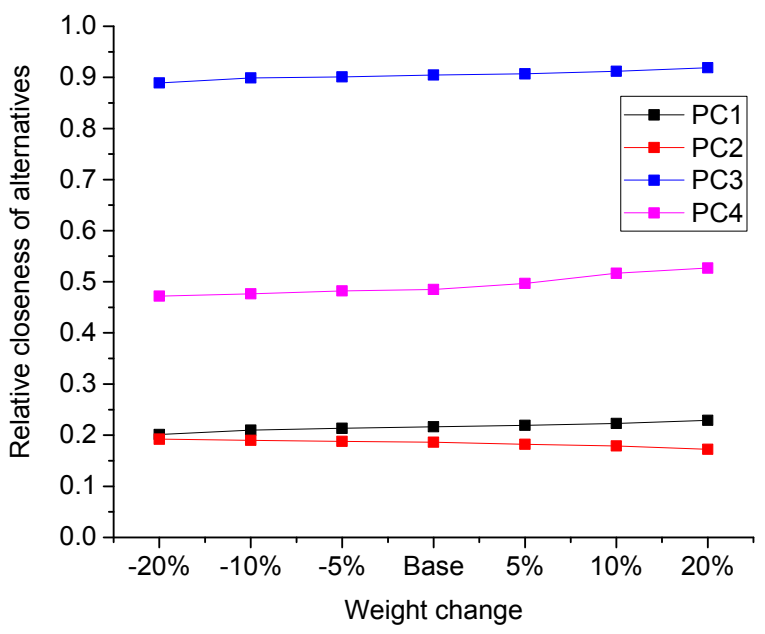

Figure 4. Sensitivity analysis result of society criteria.

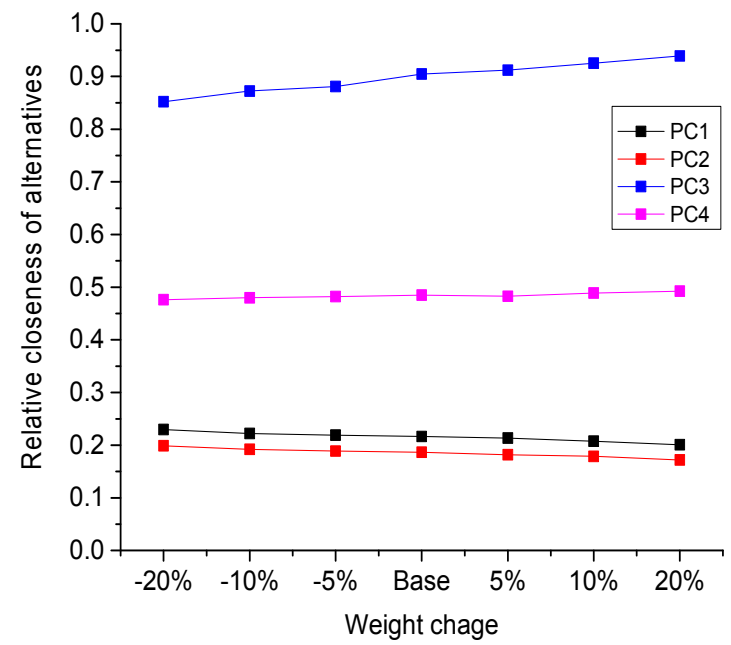

Figure 5. Sensitivity analysis result of environment criteria. 


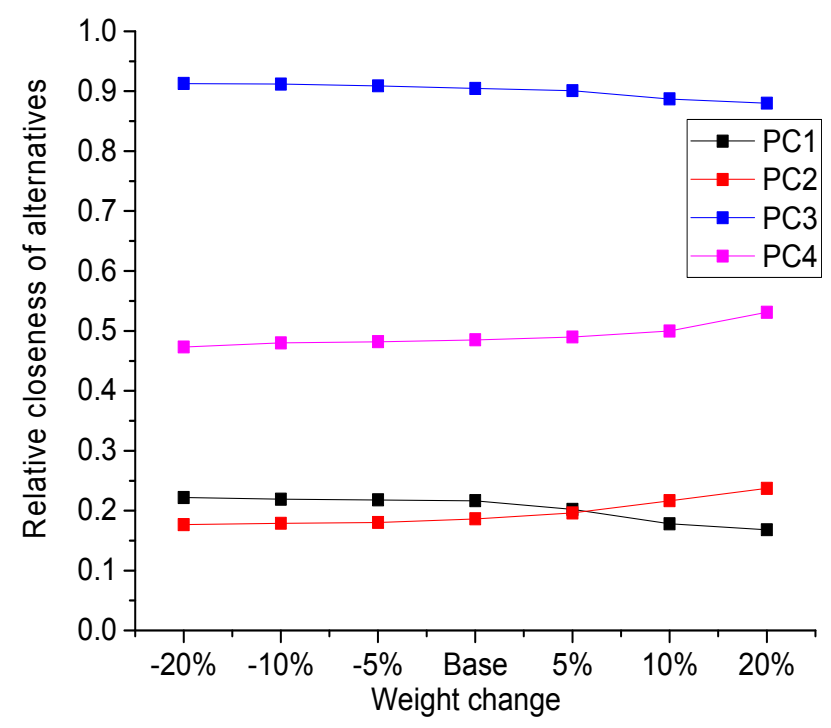

Figure 6. Sensitivity analysis result of flexibility criteria.

From the above analysis, we can see that the partner combination $P C_{3}$ always is the optimal alternative no matter how the criteria weights change using the integrated fuzzy EW-AHP and TOPSIS methodology. It indicates that the partner combination selection result, by employing integrated fuzzy EW-AHP and TOPSIS approach, is robust and effective.

\section{Conclusions}

In this paper, an integrated fuzzy EW-AHP and TOPSIS approach is proposed for evaluating partner combinations for JDA for online shopping. First, the partner combination evaluation index system is obtained using the ESEF framework based on the academic literature and experts that cooperated with our project team. The index system not only considers the economic factors, but also considers the societal, environmental and flexibility factors for sustainability.

Then, an integrated fuzzy EW-AHP approach is employed to determine the criteria weights taking objective and subjective factors of experts into consideration. At the same time, a fuzzy TOPSIS approach is used to select the optimal partner combination for JDA. In order to further verify the validity of the methodology, this paper selects the index data of partner combinations of JDA in Chongqing City, and applies the methodology to the empirical research. The results show that the proposed methodology is robust and effective, which has certain significance and reference for establishing a stable and sustainable JDA for online shopping.

The limitation of the proposed methodology is that the decision makers need to be proficient in the use of the criteria weights. If they lack the professional experience, this will impact on the results obtained. Another limitation is the lack of quantitative calculation methodology for criteria combination performance.

Taking the fast development of our society into consideration, in future studies, and the evaluation criteria system will be updated to move with the times. It is worth mentioning that the weights of criteria may need to be re-determined with the changes of the external environment. In the future, it is also necessary to develop a computer-based application system that supports decision making as it can speed up the implementation of proposed approaches and facilitate a man-machine interaction presentation of result analysis.

Acknowledgments: This study was supported by National Science and Technology Support Program of China under Grant No. 2015BAH46F01, the Specialized Research Fund for the Doctoral Program of Higher Education of China under Grant No. 20130191110045, the Fundamental Research Funds for the Central Universities Project under Grant No. CDJZR13110048, CDJZR14110001 and 106112015CDJSK02JD05, and the Chongqing City Key Science Program Project under Grant No. cstc2014yykfA40006, cstc2015yykfC60002 and cstc2012ggC00001. 
We would like to thank the editors and the anonymous reviewers for their suggestions in improving the quality of this paper, and we are also grateful to the other people in the team of "City Joint Distribution for Online Shopping Logistics" for collaboration and discussion.

Author Contributions: Yandong He and Xu Wang built the evaluation index system and developed the integrated fuzzy EW-AHP and TOPSIS method together. Yandong He completed the paper. Yun Lin and Fuli Zhou provided support in performing the data analysis. All authors have read and approved the final manuscript.

Conflicts of Interest: The authors declare no conflict of interest.

\section{References}

1. Qin, K. Study on consumption trends of 11.11 under Internet in China. Electron. Commer. 2016, 1, 1-2.

2. Yu, B.; Wu, S.; Du, G. Branch Model Simulation for Express Logistics Service System Evaluation under Online Shopping. Chin. J. Manag. Sci. 2014, 22, 72-78.

3. Ramanathan, $\mathrm{R}$. The moderating roles of risk and efficiency on the relationship between logistics performance and customer loyalty in e-commerce. Transp. Res. Part E 2010, 46, 950-962. [CrossRef]

4. Xu, S.X.; Cheng, M.; Huang, G.Q. Efficient intermodal transportation auctions for B2B e-commerce logistics with transaction costs. Transp. Res. Part B Methodol. 2015, 80, 322-337. [CrossRef]

5. Daly, S.P.; Cui, L.X. E-logistics in China: Basic problems, manageable concerns and intractable solutions. Ind. Mark. Manag. 2003, 3, 235-242. [CrossRef]

6. Wang, X.; Zhan, L.; Ruan, J.; Zhang, J. How to Choose “Last Mile" Delivery Modes for E-Fulfillment. Math. Probl. Eng. 2014, 1, 1-11. [CrossRef]

7. National Urban Distribution Development Guidelines. Available online: http://paper.ce.cn/jjrb/html/ 2013-10/28/content_175334.htm (accessed on 28 October 2013).

8. Medium and Long Term Development Plan for Logistics. Available online: http://www.gov.cn/zhengce/ content/2014-10/04/content_9120.htm (accessed on 4 October 2014).

9. Zhang, X. Joint Distribution Patterns and Decision-Making Paths for Terminal Logistics: Based on Supply and Demand Analysis of Electric Business Logistics and Community Service. Res. Financ. Econ. Issues 2013, $3,123-129$.

10. Ge, X.; Wang, X.; Deng, L. Research on Open and Dynamic Vehicle Routing Problems Based on Joint Distribution. J. Ind. Eng. Eng. Manag. 2013, 27, 60-68.

11. Zhou, J.; Zhong, X. TAOBAO Logistics Model Based on Joint Distribution// LISS 2014; Springer: Berlin/Heidelberg, Germany, 2015; pp. 29-33.

12. Adetiloye, T.O. Collaboration Planning of Stakeholders for Sustainable City Logistics Operations; Concordia University: Montreal, Canada, 2012.

13. Wei, Z.L.; Sun, J.Q. A City-based Joint Distribution Model for Small and Medium-Sized Electronic Enterprises. J. Beijing Jiaotong Univ. 2015, 14, 104-110.

14. Yang, P.J.; Hao, H.U.; Wang, J.J.; An, F. Location Model for Terminals of Urban Distribution under E-commerce Environment. Ind. Eng. Manag. 2014, 19, 35-40.

15. Zhang, Q. Research on Optimizing Scheme for City Logistics Based on Joint Distribution. China Soft Sci. 2009, S1, 290-295.

16. Zhang, X.; Yuan, Z. The Platform and Collaborative Operating Model of "Wisdom Cloud Logistics" in Online Shopping Era. Forum Sci. Technol. China. 2013, 7, 99-104.

17. Zhou, L.; Lin, Y.; Wang, X.; Zhao, Q.W. Research on capacitated multiclass terminal location-heterogeneous vehicle routing for urban distribution under online shopping. Comput. Integr. Manuf. Syst. 2016. in press.

18. Awasthi, A.; Adetiloye, T.; Crainic, T.G. Collaboration partner selection for city logistics planning under municipal freight regulations. Appl. Math. Model. 2015, 40, 510-525. [CrossRef]

19. Cruijssen, F.; Cools, M.; Dullaert, W. Horizontal cooperation in logistics: Opportunities and impediments. Transp. Res. Part E Logist. Transp. Rev. 2007, 43, 129-142. [CrossRef]

20. Castro, I.; Casanueva, C.; Galán, J.L. Dynamic evolution of alliance portfolios. Eur. Manag. J. 2014, 32, 423-433. [CrossRef]

21. Kahraman, C.; Onar, S.C.; Oztaysi, B. Fuzzy Multicriteria Decision-Making: A Literature Review. Int. J. Comput. Intell. Syst. 2015, 8, 637-666. [CrossRef] 
22. Mardani, A.; Jusoh, A.; Zavadskas, E.K. Fuzzy multiple criteria decision-making techniques and applications-Two decades review from 1994 to 2014. Expert Syst. Appl. 2015, 42, 4126-4148. [CrossRef]

23. Mardani, A.; Jusoh, A.; MD Nor, K.; Khalifah, Z.; Zakwan, N.; Valipour, A. Multiple criteria decision-making techniques and their applications-a review of the literature from 2000 to 2014. Econ. Res. Ekonomska Istraživanja 2015, 28, 516-571. [CrossRef]

24. Chan, F.T.S.; Kumar, N.; Tiwari, M.K.; Lau, H.C.W.; Choy, K.L. Global supplier selection: A fuzzy-AHP approach. Int. J. Prod. Res. 2008, 46, 3825-3857. [CrossRef]

25. Behzadian, M.; Kazemzadeh, R.B.; Albadvi, A.; Aghdasi, M. PROMETHEE: A comprehensive literature review on methodologies and applications. Eur. J. Oper. Res. 2010, 200, 198-215. [CrossRef]

26. Behzadian, M.; Khanmohammadi Otaghsara, S.; Yazdani, M.; Ignatius, J. A state-of the-art survey of TOPSIS applications. Expert Syst. Appl. 2012, 39, 13051-13069. [CrossRef]

27. Mardani, A.; Zavadskas, E.K.; Govindan, K.; Amat Senin, A.; Jusoh, A. VIKOR Technique: A Systematic Review of the State of the Art Literature on Methodologies and Applications. Sustainability 2016, 8, 37. [CrossRef]

28. Govindan, K.; Jepsen, M.B. ELECTRE: A comprehensive literature review on methodologies and applications. Eur. J. Oper. Res. 2016, 250, 1-29. [CrossRef]

29. Chen, S.H.; Wang, P.W.; Chen, C.M.; Lee, H.T. An analytic hierarchy process approach with linguistic variables for selection of an R\&D strategic alliance partner. Comput. Ind. Eng. 2010, 58, 278-287.

30. Liao, H.; Xu, Z.; Zeng, X.J. Hesitant fuzzy linguistic VIKOR method and its application in qualitative multiple criteria decision making. IEEE Trans. Fuzzy Syst. 2015, 23, 1343-1355. [CrossRef]

31. Feng, B.; Fan, Z.P.; Ma, J. A method for partner selection of codevelopment alliances using individual and collaborative utilities. Int. J. Prod. Econ. 2010, 124, 159-170. [CrossRef]

32. Govindan, K.; Rajendran, S.; Sarkis, J.; Murugesan, P. Multi criteria decision making approaches for green supplier evaluation and selection: A literature review. J. Clean. Prod. 2015, 98, 66-83. [CrossRef]

33. Govindan, K.; Soleimani, H.; Kannan, D. Reverse logistics and closed-loop supply chain: A comprehensive review to explore the future. Eur. J. Oper. Res. 2015, 240, 603-626. [CrossRef]

34. Pidduck, A.B. Issues in supplier partner selection. J. Enterp. Inf. Manag. 2004, 19, 262-276.

35. Cui, X.; Gong, L.; Chen, Y. Determining Factors in TNCs' University R\&D Partner Selection: An Empirical Study Based on China's Data. Trans. Corp. Rev. 2009, 1, 24-35.

36. Karlson, B.; Callagher, L. Which university to partner with: An investigation into partner selection motives among small innovative firms. Int. J. Innov. Manag. 2012, 16. [CrossRef]

37. Amida, A.; Ghodsypourb, S.H.; O’Brienc, C. A weighted additive fuzzy multiobjective model for the supplier selection problem under price breaks in a supply Chain. Int. J. Prod. Econ. 2009, 121, 323-332. [CrossRef]

38. Yeh, W.C.; Chuang, M.C. Using multi-objective genetic algorithm for partner selection in green supply chain problems. Expert Syst. Appl. 2011, 38, 4244-4253. [CrossRef]

39. Niu, S.H.; Ong, S.K.; Nee, A.Y.C. An enhanced ant colony optimiser for multi-attribute partner selection in virtual enterprises. Int. J. Prod. Res. 2012, 50,1-18. [CrossRef]

40. Dao, S.D.; Abhary, K.; Marian, R. Optimisation of partner selection and collaborative transportation scheduling in Virtual Enterprises using GA. Expert Syst. Appl. 2014, 41, 6701-6717. [CrossRef]

41. Wan, S.P.; Wang, F.; Lin, L.-L.; Dong, J.-Y. An intuitionistic fuzzy linear programming method for logistics outsourcing provider selection. Knowl. Based Syst. 2015, 82, 80-94. [CrossRef]

42. Erkayman, B.; Gundogar, E.; Yılmaz, A. An integrated fuzzy approach for strategic alliance partner selection in third-party logistics. Sci. World J. 2012, 2012, 269-276. [CrossRef] [PubMed]

43. Su, J.; Chen, J. Multilevel Grey Evaluation Method for Logistics Partner Selection. Oper. Res. Manag. Sci. 2006, 3, 66-70.

44. Büyüközkan, G.; Feyzioğlu, O.; Nebol, E. Selection of the strategic alliance partner in logistics value chain. Int. J. Prod. Econ. 2008, 113, 148-158. [CrossRef]

45. Li, L.; Liu, F.; Li, C. Customer satisfaction evaluation method for customized product development using Entropy weight and Analytic Hierarchy Process. Comput. Ind. Eng. 2014, 77, 80-87. [CrossRef]

46. Guo, S.; Zhao, H. Optimal site selection of electric vehicle charging station by using fuzzy TOPSIS based on sustainability perspective. Appl. Energy 2015, 158, 390-402. [CrossRef]

47. Hayel, Y.; Quadri, D.; Jimenez, T.; Brotcorne, L. Decentralized optimization of last-mile delivery services with non-cooperative bounded rational customers. Ann. Oper. Res. 2014, 1-19. [CrossRef] 
48. Soda, G.; Furlotti, M. Bringing Tasks Back In: An Organizational Theory of Resource Complementarity and Partner Selection. J. Manag. 2014. [CrossRef]

49. Xu, L.; Shi, J.J. Dynamic Stability for Alliance: Theory Based on Interdependence Balance. China Ind. Econ. 2010, 30, 97-107.

50. Jiang, X.; Li, Y.; Gao, S. The stability of strategic alliances: Characteristics, factors and stages. J. Int. Manag. 2008, 14, 173-189. [CrossRef]

51. Carter, J.R.; Maltz, A.; Maltz, E.; Goh, M.; Yan, T. Impact of culture on supplier selection decision making. Int. J. Logist. Manag. 2010, 21, 353-374. [CrossRef]

52. Pilot Measures for the Discharge of Volatile Organic Compounds. Available online: http://www.envir.gov.cn/ info/2015/12/1221-029.htm (accessed on 18 June 2015).

53. Zadeh, L.A. Fuzzy sets. Inform. Control 1965, 8, 338-353. [CrossRef]

54. Liu, P.; Zhang, X. Research on the supplier selection of supply chain based on entropy weight and improved ELECTRE-III method. Int. J. Prod. Res. 2011, 49, 637-646. [CrossRef]

55. Tavana, M.; Caprio, D.D.; Santos-Arteaga, F.J.; O'Connor, A. A Novel Entropy-Based Decision Support Framework for Uncertainty Resolution in the Initial Subjective Evaluations of Experts: The NATO Enlargement Problem. Decis. Support Syst. 2015, 74, 135-149. [CrossRef]

56. Tavana, M. A Priority Assessment Multi-criteria Decision Model for Human Spaceflight Mission Planning at NASA. J. Oper. Res. Soc. 2006, 57, 1197-1215. [CrossRef]

57. Hwang, C.L.; Lai, Y.J.; Liu, T.Y. A new approach for multiple objective decision making. Comput. Oper. Res. 1993, 20, 889-899. [CrossRef]

58. Opricovic, S.; Tzeng, G.H. Compromise solution by MCDM methods: A comparative analysis of VIKOR and TOPSIS. Eur. J. Oper. Res. 2004, 156, 445-455. [CrossRef]

59. Mardani, A.; Jusoh, A.; Zavadskas, E.K.; Cavallaro, F.; Khalifah, Z. Sustainable and Renewable Energy: An Overview of the Application of Multiple Criteria Decision Making Techniques and Approaches. Sustainability 2015, 7, 13947-13984. [CrossRef]

60. Khalili-Damghani, K.; Sadi-Nezhad, S.; Tavana, M. Solving Multi-Period Project Selection Problems with Fuzzy Goal Programming Based on TOPSIS and a Fuzzy Preference Relation. Inf. Sci. 2013, 252, 42-61. [CrossRef]

61. Junior, F.R.L.; Osiro, L.; Carpinetti, L.C.R. A comparison between Fuzzy AHP and Fuzzy TOPSIS methods to supplier selection. Appl. Soft Comput. 2014, 21, 194-209. [CrossRef]

62. Lan, R.; Fan, J.L. TOPSIS Decision-Making Method for Three Parameters Interval-Valued Fuzzy Sets. Syst. Eng. Theory Pract. 2009, 29, 129-136. [CrossRef]

(C) 2016 by the authors; licensee MDPI, Basel, Switzerland. This article is an open access article distributed under the terms and conditions of the Creative Commons by Attribution (CC-BY) license (http://creativecommons.org/licenses/by/4.0/). 